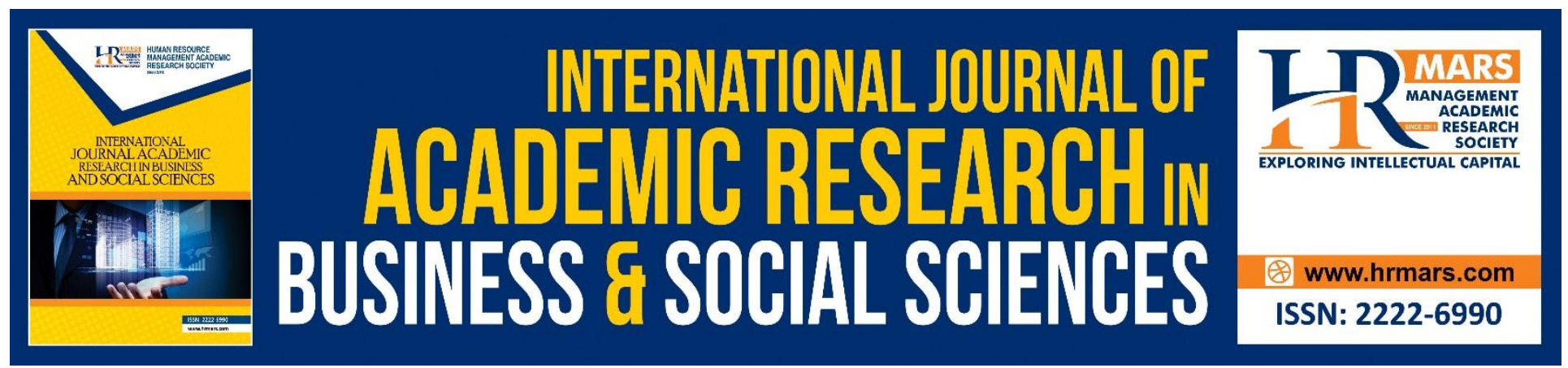

\title{
The Risk of Cardiovascular Disease Among Standard Six Tamil Schools Student's in the State of Kedah
}

Kumaran Gengatharan \& Azali bin Rahmat

To Link this Article: http://dx.doi.org/10.6007/IJARBSS/v10-i6/7467

DOI:10.6007/IJARBSS/v10-i6/7467

Received: 02 April 2020, Revised: 04 May 2020, Accepted: 08 June 2020

Published Online: 15 June 2020

In-Text Citation: (Gengatharan \& Rahmat, 2020)

To Cite this Article: Gengatharan, K., \& Rahmat, A. bin. (2020). The Risk of Cardiovascular Disease Among Standard Six Tamil Schools Student's in The State of Kedah. International Journal of Academic Research in Business and Social Sciences, 10(6), 997-1005.

Copyright: (C) 2020 The Author(s)

Published by Human Resource Management Academic Research Society (www.hrmars.com)

This article is published under the Creative Commons Attribution (CC BY 4.0) license. Anyone may reproduce, distribute, translate and create derivative works of this article (for both commercial and non-commercial purposes), subject to full attribution to the original publication and authors. The full terms of this license may be seen

at: http://creativecommons.org/licences/by/4.0/legalcode

Vol. 10, No. 6, 2020, Pg. 997 - 1005

http://hrmars.com/index.php/pages/detail/IJARBSS

JOURNAL HOMEPAGE

Full Terms \& Conditions of access and use can be found at http://hrmars.com/index.php/pages/detail/publication-ethics 


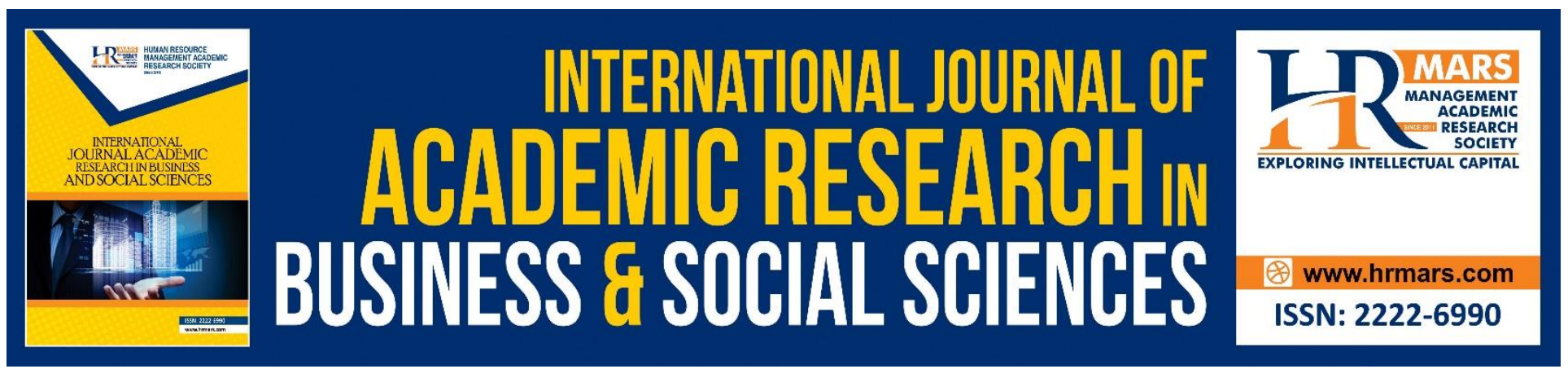

\title{
The Risk of Cardiovascular Disease Among Standard Six Tamil Schools Student's in The State of Kedah
}

\author{
Kumaran Gengatharan \& Azali bin Rahmat \\ Faculty of Sports Science and Training, Universiti Pendidikan Sultan Idris, 35900 Tanjung Malim, \\ Perak Malaysia
}

\begin{abstract}
The study aims to identify the risk of cardiovascular disease among standard six students who are studying in Tamil schools at Kedah. The design used in this study is the ex-post-facto study embodied by Cohen, Manion and Morrison (2018). The purpose of this study is to identify the risk of cardiovascular disease by evaluating and comparing the body mass index (BMI), blood pressure (BP) and waist ratio to height ( $\mathrm{WHtR})$ of standard six students. The instruments used in the study were the body mass index (BMI), blood pressure (BP) and waist ratio to height (WHtR). Data from those tests were correlated to determine the risk of cardiovascular disease among standard six students. Data are analyzed using 'SPSS' version 22. The findings showed that there is a strong positive relationship (1.00) between systolic blood pressure (SBP) and diastolic blood pressure (DBP). At the same time, there is a positive moderate (.748) relationship between BMI and WHtR amongst the pupils. The findings of this study can conclude and explain that if a student does not maintain health by adopting a healthy lifestyle, it is likely to lead them to obesity and risk of cardiovascular disease.
\end{abstract}

Keywords: Cardiovascular Disease, Year Six Students, Tamil School, Healthy Lifestyle and Ex-Post Facto.

\section{Introduction}

Cardiovascular disease is a dangerous disease that affects the heart. There are different categories in cardiovascular disease, but the most known is a heart attack and stroke. Cardiovascular disease inter-related with the lifestyle of an individual such as smoking, consuming alcohol, lack of exercise, unhealthy eating habits, unhealthy lifestyle and genetic (WHO, 2018). According Fardy (1996), three main factors can cause an individual to get a cardiovascular disease, which are hypertension, obesity and a sedentary lifestyle. The risk of cardiovascular disease can be divided into two factors, which are manipulated and de-manipulated factor. The manipulated factors are smoking habits, the amount of cholesterol in the blood, high blood pressure, diabetes, obesity, stress and exercise, whereas de-manipulated features are genetic, gender and age. 
INTERNATIONAL JOURNAL OF ACADEMIC RESEARCH IN BUSINESS AND SOCIAL SCIENCES Vol. 10, No. 6, June, 2020, E-ISSN: 2222-6990 @ 2020 HRMARS

The report on health by Harvard school reported that cardiovascular disease has led to death all over the world in the year 1990, which affected about 6.3 million life and 2.7 million of life from other developed countries. Based on Gram (1995), cardiovascular disease is known as a disease of developed countries that causes death and common health problems even in Asia countries like Japan and Singapore. In Malaysia, cardiovascular disease has become the second killer amongst all the races, age and gender. Every year, the number of death caused by cardiovascular disease is increasing. According to Ramly (1995), the number of death caused by cardiovascular disease is around 26.05 percent, and the number of death caused by this disease is similar in the same year, with 27.24 percent.

\section{Problem Statement}

Nowadays, the issue of pupils who do not wish to get themselves involve during the Physical Education class has become a common problem. Obese pupils usually do not participate in any physical activities because they feel shy. According to Smustaffa Embong (2016), nowadays, obesity among pupils is becoming serious, where there is research that says that 15 percent of pupils from the age of 12 until 19 are overweight. This statement is supported by Poh Bee Koon (2015), 21.4\% of teenagers in urban and $16 \%$ in rural areas face excessive bodyweight problem. In reality, a total of $6 \%$ of teenagers has been hospitalized due to diabetes, and this figure is increasing every year.

Maffeis, Pietrobelli, Grezzani, Provera (2011) state that a few epidemiology studies support the relationship hypothesis between adiposity and cardiovascular disease risk start in early life. The space to keep adipose tissue owned metabolic activity that is different and correlated with disease risk as fat distributions function in the body. Meanwhile, Kuba, Leone and Damini (2013), emphasized that WHtR as a level indicator that is useful to identify metabolic cardio disease risk. Apart from that, Kuba et al. (2013) indicated that obesity could be measurable in our body using $\mathrm{BMI}$ and waist circumference, especially that is associated with cardio risk metabolic.

Apart from that, some pupils declined to take part in physical activity because they have asthma and breathing problem. This shows that the pupil with cardiovascular disease also refuses to take part in Physical Education class. Based on the researcher's observation, most pupils do not know about the real name of cardiovascular disease. They also do not know the types of cardiovascular disease, risk factors, and symptom that exist in all the kind of cardiovascular disease. Pupil's knowledge of cardiovascular disease is still low, and plenty of information is not identified. Therefore, researchers conduct a study on the risk of cardiovascular disease among Tamil school pupils who are 12-years-old to get an overview of the pupils' health risk.

\section{Research Objective}

Identify the risk of cardiovascular disease among Year 6 pupils in Tamil schools at Kedah State by making BMI test correlation, BP and WHtR.

\section{Research Question}

i. What is the relationship between BMI test, BP and WHtR with cardiovascular disease risk?

\section{Research Hypothesis}

i. There is a significant relationship between BMI test, BP and WHtR with cardiovascular disease risk. 
INTERNATIONAL JOURNAL OF ACADEMIC RESEARCH IN BUSINESS AND SOCIAL SCIENCES

Vol. 10, No. 6, June, 2020, E-ISSN: 2222-6990 @ 2020 HRMARS

\section{Study Limitations}

The limitations of this study are the pupils chosen from Arumugam Pillai Tamil school in Kedah State. There are 94 pupils as the representative from the school. This test involved 47 boys and 47 girls. The data collection for the entire analysis was collected during Physical Education class. The pupils with health problems were not included in this study; neither were allowed.

\section{Past Research}

Stephen, John, Dennis, Philip (1999), and Thomas did the study on fat distribution in the body and cardiovascular risk factors among children and youth. A total of 127 children and youth age from 9 to 17 years has been involved in this study. Dual absorptiometry x-ray energy used to measure total and percentage of fat. The dependent variable is a lipid, SBP lipoprotein and DBP. Analysis of multiple regression shows that there is a link free for triglyceride and HDL cholesterol with the age factor and fat distribution. At the same time, SBP is height, and fat distribution for blood pumping to the heart is height, race, sex, and fat distribution. Research results showed that fat distribution showed that fat relation free on risk is important than the factor of cardiovascular risk than the percentage of fat in the body of the children.

McNiece, Poffenbarger, Turner, Franco, Sorof, and Portman (2007) carried out a study on high blood pressure convention and pre-high blood pressure among youth. A pilot study was carried out by using the subject of 6790 teenagers aged 11 to 17 years in Houston schools, Texas, from the year 2003 to 2005. Height, weight and BP reading are taken to assess the risk factor of cardiovascular.

BP test in early testing shows $81.1 \%$ from the youth have blood pressure at normal level, $9.5 \%$ in pre-compressed level high blood, and $9.4 \%$ teenagers having high blood pressure $(8.4 \%$ at level 1 , while $1 \%$ at level 2). After three checks, $81.1 \%$ of teenagers record BP is normal, $15.7 \%$ suffer pre-compressed high blood, and $3.2 \%$ de-diagnose having high blood pressure $(2.6 \%$ at level $1,0.6 \%$ at level 2). High blood pressure and pre-compressed high blood are advancing by increasing BMI. Apart from that, gender aspects and race are also associated with pre-high blood pressure. Classification guideline usage reveals that approximately $20 \%$ of teenagers have the risk to suffer from high blood pressure. Kuba et al. (2013) had conducted a study on WHtR accuracy as a level as an indicator that is useful to identify cardio disease risk metabolic in children aged 6 to 10 years. This pilot study has been carried out towards 175 samples, which are selected from youth and children treatment center in Campos, Rio de Janeiro, Brazil. Samples have been classified based on the standard of WHO (2007), as normal body weight (z BMI score >-1 and $<1$ ), or excess of body weight / obese ( $\geq$ BMI -1$)$. SBP, DBP, glycemia and Lipoprotein Density Low (LDL), High-Density Lipoprotein (HDL) and triglyceride (TG) have been analyzed. Study found that there is a significant relationship between WHtR and z BMI score $(r=0.88, p<0.0001)$, SBP $(r=0.51$, $p<0.0001)$, DBP $(r=0.49, p<0.0001)$, LDL $(r=0.25, p<0.0008$, HDL $(r=-0.28, p<0.0002)$ and TG $(r=$ $0.26, p<0.0006$. WHtR and BMI area under the curve is the same to all cardio parameter metabolic. The study found out that WHtR deduction value $>-0.47$ is sensitive as one of the cardio parameter metabolic. Therefore, WHtR is sensitive and accurate, just like BMI, as stated by WHO (2007), whereby the waist size care is important in reducing cardio risk metabolic.

Musthaq, Muhammad Umair (2011), had also conducted a study on the size of waist, hip waist (WC) ratio, WHtR, obesity and risk of cardiovascular towards 1860 among Lahore, Pakistan children from 5 to 12 years. Retrieval result research showed that WC increased among female and 
INTERNATIONAL JOURNAL OF ACADEMIC RESEARCH IN BUSINESS AND SOCIAL SCIENCES Vol. 10, No. 6, June, 2020, E-ISSN: 2222-6990 @ 2020 HRMARS

male children. WC for children in Pakistan is higher compared to children in Hong Kong and British and is lower compared to children in Iran, German and Switzerland. WHR shows that decision is high among boys while higher among female children until nine years and decline after that. Obesity, including higher grades in urban with high socio-economic (SES) standard, high-income neighborhood and higher parent education. Children who learn in a higher class (AOR 5.11, 95\% Cl 1,76-14,85) and those living in urban with high socio-economic (AOR 82,34, 95\% Cl 15.76 - 43.31) showing top results significant than apparent. Urban with high socioeconomic and parent education that is higher shows notable with WC high and higher WHtR while higher grade shows significant with higher WC and shows higher socio-economic children are suffering from cardiovascular disease.

\section{Survey Design}

This study employs an ex-post facto design. The ex-post facto study is suitable to use for research of attribute variables, as mentioned by Cohen et al. (2018). The facto ex-post study is related to the study on effect and reason that has already happened. Kelinger (1973) defines facto ex-post study as "systematic, empirical inquiry in which the scientist does have direct control of independent variables because of their manifestations have already occurred or because they are inherently noted as a manipulative note." Design involves data collection from the same samples. The researcher has no control towards variables and cannot manipulate free variables which resulted in some effect towards the dependent variable.

\section{Research Sample}

As a whole, there are 1295 primary school children enrolled in Tamil school at Kedah. Chua (2006) said sampling is related to the process of choosing the number of samples than the population made by research respondents. Sampling techniques are not random, but sampling used in this study focuses on year six pupils from Tamil schools in Kedah. According to Yamane (1967), the sample size determines the schedule, 94 pupils elected with $\pm 7 \%$ error to become the research sample. Samples were chosen from SJK Arumugam Pillai, Kedah. They consist of 47 boys and 47 girls.

\section{Study Instrument}

Index test body mass (BMI), blood pressure (BP) and waist ratio to height (WHtR) used by the process of data collection and study relation with cardiovascular disease. BMI of data collection and study relation with cardiovascular disease. BMI of the pupils depicts the body shape. At the same time, WHtR also explained fat distribution around the hip, stomach and BP examination; on the other hand, it reveals pupil heart strength circulating the whole body.

\section{Data Collection Procedure}

After getting permission from the Malaysian Ministry of Education Department, Kuala Muda District and SJKT Arumugam Pillai school's headmaster, the researchers began their study towards 94 Year, six pupils. The researcher also obtained approval from the pupils' parents. All the test was carried out during Physical Education class without interrupting the teaching and learning period. Four Physical Education specialist teachers in the school help the researcher to collect the data.

Data collection for BMI tests is performed in stages which are height and weight. Two different brands, namely 'Omron, used to measure height and weight so that they can obtain more 
INTERNATIONAL JOURNAL OF ACADEMIC RESEARCH IN BUSINESS AND SOCIAL SCIENCES

Vol. 10, No. 6, June, 2020, E-ISSN: 2222-6990 @ 2020 HRMARS

accurate data. For the BP test, pupils tested during their pulse rate in stationary mode and asked to stay in the place while WHtR was measured using tape. It is to measure the waist circumference, and pupils requested to stand up when taking waist circumferences.

\section{Data Analysis}

The data analyzed by using 'SPSS' version 22. BMI data, BP and WHtR pupil according to gender have been analyzed by the researcher. The correlation test between all three tests was done to detect cardiovascular disease risk rates among sixth-year students.

\section{Study Findings}

This part will explain the testing result that was done towards sixth-year students and the direct relationship between test norms. The correlation coefficient value used in the analysis is between +1.00 and does not exceed or less than the value. Positive correlation coefficient showing direct contact between two variables. Negative correlation coefficient showing over turn relationship between two variables. Correlation coefficient number, on the other hand, showed the strength of the relationship and trend of the relationship between variables.

For example, +.9 (graph raise) shows the strength of relationship degree that is equal to -9 (graph decline) with the trend of relationship that is different (boarding and decline). Safrit and Wood (1995), appraise +.80 correlation coefficient size to 1.00 high, +60 to .79 as medium height, +.40 to medium $.59,+.20$ to low .39 and +.00 to .19 as no connection between two variables.

Figures and Tables

Table 1: Correlation of BMI, WHtR, SBP dan DBP

\begin{tabular}{ll|l|l|l|l}
\hline & & BMI & WHtR & SBP & DBP \\
\hline BMI & Pearson Correlation & 1 & $.748^{* *}$ & $.438^{* *}$ & $.438^{* *}$ \\
& Sig. (2-tailed) & & .0001 & .0001 & .0001 \\
& $\mathrm{~N}$ & 94 & 94 & 94 & 94 \\
\hline WHtR & Pearson Correlation & $.748^{* *}$ & 1 & $.377^{* *}$ & $.377^{* *}$ \\
& Sig. (2-tailed) & .0001 & & .0001 & .0001 \\
& $\mathrm{~N}$ & 94 & 94 & 94 & 94 \\
\hline SBP & Pearson Correlation & $.438^{* *}$ & $.377^{* *}$ & 1 & $1.000^{* *}$ \\
& Sig. (2-tailed) & .0001 & .0001 & & .0001 \\
& $\mathrm{~N}$ & 94 & 94 & 94 & 94 \\
\hline DBP & Pearson Correlation & $.438^{* *}$ & $.377^{* *}$ & $1.000^{* *}$ & 1 \\
& Sig. (2-tailed) & .0001 & .0001 & .0001 & \\
& $\mathrm{~N}$ & 94 & 94 & 94 & 94
\end{tabular}

Table1 shows that there is a significant relationship with $(p=.0001)$ and positive $(r=.748)$ medium height correlation between BMI with WHtR while relationship that is significant $(p=.0001)$ between BMI with BP reading with positive $(r=.438)$ medium positive correlation. This shows BMI and WHtR pupil have direct contact (positive) and interconnected by significance. Apart from that, the WHtR relationship with BP is significant $(p=.0001)$ with a relationship correlation link 
INTERNATIONAL JOURNAL OF ACADEMIC RESEARCH IN BUSINESS AND SOCIAL SCIENCES Vol. 10, No. 6, June, 2020, E-ISSN: 2222-6990 @ 2020 HRMARS

relationship that is low $(r=.377)$. Both SBP and DBP with BMI pupil on the other hand showing significant $(p=.0001)$ relationship with positive $(r=.438)$ medium correlation.

Apart from that, the significant relation $(p=.0001)$ with positive $(p=.377)$ low correlation between BP (SBP and DBP) with WHtR. However, SBP and DBP have significant relation $(p=.0001)$ high ( $p$ $=1.00$ ) between one another. Data research showed all three BMI tests, BP and WHtR, have significant relationships with each other (hypothesis accepted).

\section{Discussion and Study Implications}

Although retrieval research does not show a correlation relationship that is high between all three tests in knowing cardiovascular disease risk among sixth-year students, retrieval BMI and WHtR have an averagely strong relationship. This shows that if the pupil does not care about their $\mathrm{BMI}$, thus it will lead to pupil body having the potential to become fat (obese physically) emerging to cardiovascular disease risk. According to Stephen, John, Khoury, Thomas \& Kimball (2001), total distributions of fat in waist have a strong relationship in causing cardiovascular disease risk. SBP reading and DBP, on the other hand, have a very strong relationship. This signifies that if a pupil does not regulate his blood pressure, it can cause cardiovascular disease. This statement is supported by

McNiece et al. (2007), which states that an increment in BP can lead to the cardiovascular increase of risk. Therefore, the data emphasized in the study reveals there is a significant relationship between $\mathrm{BMI}, \mathrm{BP}$ and $\mathrm{WHtR}$. This phenomenon can improve risk to cardiovascular among sixth year students who will step into the secondary school environment soon. This study implicates that pupils should regulate their lifestyle by exercising regularly, eat balanced food, avoid bad habits like smoking, drinking and maintain the blood count in the body. This study will also create awareness for pupils to transform themselves into human capital that is safe and healthy by performing good deeds to oneself, family, society and country. Although there are various studies on cardiovascular disease that were studied overseas but, in our country, it still lacks in deep revelation on cardiovascular disease risk among pupils. Therefore, the researcher proposes to the future researcher to conduct the study on the cardiovascular disease which is more extensive and indepth for all primary and secondary schools throughout the country by using instrument and test that are more sophisticated to identify health problems such as cardiovascular disease at initial stage so that we can cure the health problem from deteriorating.

\section{Acknowledgment}

We thank our colleagues from Universiti Pendidikan Sultan Idris, who provided insight and expertise, which significantly assisted the research. However, they may not agree with all of the interpretations/conclusions of this paper. We thank Prof Madya Dr. Azali Bin Rahmat for his assistance with methodology, and Mr.Hisahamudin, Senior Lecturer, Universiti Pendidikan Sultan Idris for his comments that have greatly improved the manuscript.

I also would like to show our gratitude to the Mr.Najib, Universiti Pendidikan Sultan Idris, for sharing his pearls of wisdom with us during this research, and we thank 3 "anonymous" reviewers for their so-called insights. We are also immensely grateful to Ms.Szarmilaa Dewie Krishnan, Universiti Kebangsaan Malaysia, for her comments on an earlier version of the manuscript. However, any errors are our own and should not tarnish the reputations of these esteemed persons. 
INTERNATIONAL JOURNAL OF ACADEMIC RESEARCH IN BUSINESS AND SOCIAL SCIENCES

Vol. 10, No. 6, June, 2020, E-ISSN: 2222-6990 @ 2020 HRMARS

\section{Corresponding Author}

Kumaran Gengatharan, Universiti Pendidikan Sultan Idris, Malaysia

Email: kumarangengatharan@gmail.com

\section{References}

Anizyn, M. L. (2011). Kajian pemakanan di kalangan remaja di kalangan remaja di kawasan Felda Bukit Ramun. Retrieved from https://anizyn.blogspot.com/2011/07/kajian-pemakanan-ukmkeperluan-diet.html.

Bernama. (2018) Malaysia mempunyai kadar diabetes tertinggi di Asia.

Chu, N. F., Wang, D. J., \& Shieh, S. M. (2001). Obesity, leptin and blood pressure among children in Taiwan: The Taipei Children's Heart Study. American journal of hypertension, 14(2), 135-140.

Chua, Y. P. (2006). Kaedah Pengkajian. Malaysia: McGraw-Hill Education.

Cohen, L., Manion, L., \& Morrison, K. (2018). Research Method of Education. (8th ed). London New York: Taylor and Francis Group.

Daniels, S. R., Morrison, J. A., Sprecher, D. L., Khoury, P., \& Kimball, T. R. (1999).

Association of body fat distribution and cardiovascular risk factors in children and adolescents. Circulation, 99(4), 541-545.

Embong, M. (2013). Nadi Diabetes. Retrieved from www.diabetesmalaysia.com.my/upload_dir/NADI\%20V2S2.pdf.

Engler, M. M., Engler, M. B., Davidson, D. M. and Slaughter, R. E. (1992). Cardiovascular disease prevention: Knowledge and attitudes of graduate nursing students. Journal of Advance. Nursing, 17: 1220-1225.

Ghee, L. K. (2012). Staying Relevant. The Medical journal of Malaysia, 67(1).

Gram, G. (1995). Major differences in cardiovascular disease risk indicators by education. status: Results from a population-based screening program. Scandinavian journal of social medicine, 23: 9-16.

Juel, C., Griffith, P. L., \& Gough, P. B. (1986). Acquisition of literacy: A longitudinal study of children in first and second grade. Journal of Educational Psychology, 78(4), 243-255.

Kerlinger, F. N. (1970). Foundations of Behavioral Research: Educational and Psychological Inquiry. London: Holt. Reinhart \& Winston.

Kuba, V. M., Leone, C., \& Damiani, D. (2013). Is the waist-to-height ratio a useful indicator of cardiometabolic risk in 6-10-year-old children?. BioMedicine Central pediatrics journal, 13(1), 91. https://doi.org/10.1186/1471-2431: 13-91

Maffeis, C., Pietrobelli, A., Grezzani, A., Provera, S., \& Tatò, L. (2001). Waist circumference and cardiovascular risk factors in prepubertal children. Obesity Research Journal, 9(3), 179-187.

McNiece, K. L., Poffenbarger, T. S., Turner, J. L., Franco, K. D., Sorof, J. M., \& Portman, R. J. (2007). Prevalence of hypertension and pre-hypertension among adolescents. The Journal of Pediatrics, 150(6), 640-644.

Yasin, M. I. A. (2008). Amalan Pemakanan Di Kalangan Remaja Di Kawasan Felda Bukit Ramun, Kulai, Johor (Degree Dissertation). Retrieved from www.fp.utm.my/epusatsumber/pdffail/ptkghdfwP/IDAASTRIEAP040458D2008TTP.

Mosca, L., Benjamin, E. J., Berra, K., Bezanson, J. L., Dolor, R. J., Lloyd-Jones, D. M., \& Zhao, 
INTERNATIONAL JOURNAL OF ACADEMIC RESEARCH IN BUSINESS AND SOCIAL SCIENCES

Vol. 10, No. 6, June, 2020, E-ISSN: 2222-6990 @ 2020 HRMARS

D. (2011). Effectiveness-based guidelines for the prevention of cardiovascular disease in Women: a guideline from the American Heart Association. Journal of the American College of Cardiology, 57(12), 1404-1423.

Mushtaq, M. U., Gull, S., Mushtaq, K., Shahid, U., Shad, M. A., \& Akram, J. (2011). Dietary behaviors, physical activity and sedentary lifestyle associated with overweight and obesity, and their socio-demographic correlates, among Pakistani primary school children. The international journal of behavioral nutrition and physical activity, 8, 130. https://doi.org/10.1186/14795868-8-130 8(1):130-135.

Safrit, M. J., \& Wood, T. M. (1995). Introduction to Measurement in Physical Education and Exercise and Exercise Science ( ${ }^{\text {rd }}$ ed.). St. Louis: Times Mirror/Mosby.

Daniels, S. R., Morrison, J. A., Sprecher, D. L., Khoury, P., \& Kimball, P. T. (1999). Association of Body Fat Distribution and Cardiovascular Risk Factors in Children and Adolescents. Circulation, 99:541-545.

World Health Organization. (1999). The World Health Report 1999 - A Safer Future. Retrieved from https://www.who.int/whr/previous1999/en/.

World Health Organization. (2007). The World Health Report 2007- a safer future: global public health security in the 21st century. Retrieved from https://www.who.int/whr/2007/en/.

World Health Organization. (1993). The World Health Report 1993 - International Classification Disease. Retrieved from https://icd.Who.int/browse10/Content/statichtml/ ICD10Volume2 en 2010.pdf.

World Health Organization. (1999). The World Health Report: 1999 - making a difference. Retrieved from https://www.who.int/whr/1999/en/.

World Health Organization. (2008). The World Health Report 2008 - Primary Health Care. Retrieved from https://www.who.int/whr/2008/en/. 